\title{
Resenha
}

\section{Violência Velada: a história de pescadoras embarcadas contada por Rose Mary Gerber ${ }^{1}$}

\author{
Patricia Jung \\ Bacharel em Administração pela Universidade Federal \\ da Fronteira Sul. Bacharel em Direito pela Universidade \\ Comunitária da Região de Chapecó. Mestranda em Direito \\ pela Universidade Comunitária da Região de Chapecó. \\ patricia_jung@outlook.com
}

\section{Arlene Renk}

Doutora e mestre em Antropologia pelo Museu Nacional, Universidade Federal do Rio de Janeiro, respectivamente em 1997 e 1990. Graduada em Letras pela UFPr. Professora titular da Unochapecó. Docente Permanente do Programa de Pós-Graduação em Ciências Ambientais, na Linha Sociedade, Ambiente e Sustentabilidade. Integra o Núcleo de Stricto Sensu em Direito da Unochapecó, no Grupo de Pesquisa Direito, Democracia e Participação Cidadã. Tem experiência em pesquisa e orientação na área de cidadania, socioambientalismo, antropologia rural, territorialidades, participação e controle social. arlene@unochapeco.edu.br

Em "Mulheres e o mar: pescadoras embarcadas, no litoral de Santa Catarina, sul do Brasil”, de forma envolvente e apaixonada pela temática, e justamente por isso quase sob a forma de um romance, Rose Mary Gerber

${ }^{1}$ Apoio: Fundação de Amparo à Pesquisa e Inovação do Estado de Santa Catarina (Fapesc) e Coordenação de Aperfeiçoamento de Pessoal de Nível Superior (Capes). 
apresenta um estudo etnográfico realizado nas cidades de Governador Celso Ramos, São Francisco do Sul e Balneário Barra Sul com 22 pescadoras. O objetivo da pesquisa, realizada para sua tese de Doutoramento, consistiu em investigar a existência de pescadoras embarcadas (em mar), e a partir disso a análise da realidade em que estão envoltas, incorrendo por reflexo, em um processo de visibilização da mulher na atividade pesqueira, seja ela embarcada ou em terra.

O capítulo inaugural "Brasil de águas: antropologia e pescas", retoma estudos já realizados sobre a pesca no Brasil, em especial em Santa Catarina. Mais importante que a condensação da temática, contudo, cabe neste momento da obra a reflexão sobre a adequação de uma antropologia específica das populações pesqueiras, haja vista que pesca e agricultura incorporam ao mesmo tempo os estudos do "campesinato", ainda que reflitam ambientes e meios de trabalho tão distintos. Nesse sentido, ainda que válido considerá-las como populações rurais, faz-se necessário considerar "as especificidades de cada qual exatamente para fortalecer a diversidade interna ao que se define atualmente como população rural”, promovendo a visibilidade da pesca diante do Estado (Gerber, 2015, p. 61). É a partir desses elementos que a autora visa a evidenciar em um primeiro momento um processo de invisibilidade oficial em relação à atividade pesqueira, a tal ponto de em sua última seção do capítulo determinar que não são exóticos o suficiente, nem citadinos o bastante para receber a atenção necessária do poder público.

$\mathrm{O}$ arcabouço de estudos analisados ainda corroborou para reafirmar a pesca como uma atividade essencialmente masculina, relegando às mulheres as atividades domésticas - que cabe destacar, são compreendidas como "obrigações" e não como trabalho -, ainda que entre as atividades estejam subentendidas aquelas relacionadas à limpeza e ao beneficiamento dos pescados. Evidente, portanto, que na lógica predominante a figura do pescador é concebida como aquele (homem) que embarca, que vai ao mar, sem considerar as atividades necessárias ao pós-pesca 
embarcada. Concepção que inclusive não está arraigada apenas no campo teórico, mas nas políticas e instituições públicas. Destarte, se já ocorre um processo de invisibilidade da atividade pesqueira, em relação às mulheres esse processo é duplicado, é oficial e acadêmico, considerando que ambos não supõem sua presença na pesca. A visibilidade da mulher na pesca é a partir de sua concepção como: "mulheres das comunidades pesqueiras, ou mulheres de pescadores”, mas raramente como pescadoras (Gerber, 2015, p. 79).

O segundo capítulo, "Mulheres pescadoras: narrativas autobiográficas”, compreende a entrevista com as 22 pescadoras integrantes da pesquisa, envolvendo a descrição de como se deu a inserção na pesca, quais e como são as atividades desenvolvidas em seu cotidiano-sejam elas domésticas, familiares ou pesqueiras -, bem como quais as dificuldades e alegrias decorrentes da pesca.

Dos relatos depreende-se novamente a centralidade do homem na pesca, seja em razão da pesca ser herança de seus pais e esposos, seja pela submissão da mulher pelo homem durante a atividade pesqueira, verificável no seguinte relato: "Eles são os mestres. Acho que, de certa forma, a gente reproduz o ser esposa e o ser camarada. Eles é que são as referências” (Gerber, 2015, p. 123). Ou ainda pela dificuldade de acesso a crédito pelo não reconhecimento da profissão de pescadora às mulheres, tema que se destaca o relato a seguir: “[...] eles não queriam fazer para mulher. Eles alegavam que mulher não pesca. Como ela vai pagar?” (Gerber, 2015, p. 110). Interessante notar que ao mesmo tempo que há certa submissão ao homem, também se constata a necessidade de reafirmação da independência em relação à figura masculina, com falas do gênero: “O barco pequeno está no nome dele. O grande vai para o meu nome” (Gerber, 2015, p. 93). 
O terceiro capítulo, "O mundo da pesca das mulheres”, inicia-se com a autora discorrendo sobre os elementos naturais - luas, ventos, marés - que afetam a atividade pesqueira, uma vez que a “[...]a ação de tais elementos remete à complexidade que norteia não apenas as saídas e chegadas das embarcações, mas o próprio ritmo dos ciclos de fartura ou escassez da pesca” (Gerber, 2015, p. 129). Ainda são abordados os instrumentos utilizados durante a pesca - embarcações, redes, bandeiras, agulhas e linhas -, as espécies de peixes cobiçadas e perigosas, e como se desenvolve o trabalho em terra após a pesca embarcada.

Mais importante do que a explicação dos elementos físicos e naturais que envolvem a pesca é o efeito que estes e a atividade em si trazem para estas mulheres: transformação do corpo - mãos, pele, saúde - e da alma - reconhecimento, coragem. Transformações vinculadas especialmente por meio daquilo que designam como "vício" pelo mar. Este é desenvolvido mediante duas vertentes, ora como uma rota de fuga dos papéis de gênero impostos à mulher: cuidar da casa, cuidar do marido e filhos; e ora um gostar que foi aprendido, que está para além do prazer de realizar a atividade, e encontra-se na necessidade financeira de continuar trabalhando.

Dando continuidade às transformações das mulheres na pesca, no capítulo seguinte, "O mundo das mulheres na pesca: aprendizados e corpos”, a autora busca compreender como o corpo se constitui em prova: de vida, de morte, de ausência, de pesca. Apoiando-se em Maluf, busca demonstrar como "somos produtos e produtores de corpos, culturas e sujeitos” (Gerber, 2015, p. 185).

Nesta discussão sobre o corpo, novamente entra em cena as divisões de gênero. Gerber deixa claro que a pesca remete a um corpo e a um gênero: o masculino. Para além das roupas e instrumentos que necessitam ser adequados ao corpo feminino, é importante ponderar que a concepção da pesca como trabalho masculino encontra-se arraigada nas próprias 
pescadoras, que definem suas atividades como de "macho", o que por consequência revela implicitamente um processo interno de divisão de quais atividades caberiam a cada gênero, evidenciando, por outro lado, como as pescadoras quebram essas barreiras. Igualmente ocorre com os homens, quando chamados a qualificar o trabalho de suas mulheres na pesca, equiparavam a sua força, coragem e destreza às de um homem. Fatos que deixam implícita a concepção de que o trabalho na pesca que é realizado adequadamente é aquele decorrente do homem.

No capítulo derradeiro, "A relação com o Estado: entre saberes, reconhecimento e (in)visibilidade, um sujeito que não se enquadra?”, Gerber realiza a reunião dos vários elementos delineados no decorrer das seções anteriores.

Como elementos que corroboram na evidenciação da invisibilização da pescadora, em primeiro lugar é colocada em xeque a imposição do saber científico em detrimento do saber tradicional, do saber fazer, uma vez que este pressupõe a superioridade do primeiro, incorrendo indiretamente em um processo "civilizatório" destas populações, com a finalidade de que tenham melhores condições de higiene e produzam dentro dos padrões esperados. Embora Gerber construa essa proposição baseada do extensionismo rural, é evidente que se trata de um processo generalizado em diferentes campos, em que as políticas públicas, projetos e leis são elaborados distantes das realidades às quais procuram abarcar, não incorporando as diferentes especificidades, e nem prestigiando o sujeito aos quais se destinam, mas pressupondo a veracidade e adequação a partir do conhecimento científico. Essa lógica ainda é perpetrada pelos técnicos que trabalham com esses instrumentos junto a essas populações, que repercutem a dificuldade de recepção das técnicas propostas, sem, no entanto, perceber que seus objetivos não fazem "eco com os seus modos de ser, viver e estar no mundo" (Gerber, 2015, p. 209). 
Nota-se, assim, que são lógicas perpetradas dentro de mecanismos que visam a priorizar a homogeneização e não diversidade, em favor de uma suposta burocracia que viabilize a precisão, o controle, a velocidade, etc. Os números são privilegiados, não por serem melhores, mas por serem o caminho mais fácil, a complexidade qualitativa é afastada por ser cara, complexa. É nesse sentido que a autora aponta para a necessidade de perversão da burocracia, de transformar o molar em molecular, a fim de que o diverso possa ser incorporado de modo adequado.

A trajetória dessa lógica dentro do ambiente pesqueiro é ilustrada por Gerber por meio da inadequação previdenciária para pescadoras. A pesca, sendo caracterizada como ambiente masculino, implica que seja considerada inexistente a presença de mulheres na atividade. Essa lógica é transportada do social para o ambiente público, de modo que o INSS passe a exigir como requisito para aposentadorias de pescadoras que estas provem serem esposas ou filhas de pescadores, pressupondo que sua existência profissional ocorra apenas a partir do homem, sozinha ela não é trabalhadora.

Além dessa problemática, ainda é saliente o fato de os órgãos oficiais considerarem pescador artesanal "aquele que vai para o mar, pesca e retorna com o produto in natura”; qualquer processo posterior não é compreendido dentro da atividade pesqueira, mas como uma atividade de beneficiamento, a qual é realizada, sobretudo, pelas mulheres. Em função disso, e por ser compreendida como uma atividade que incorpora as atividades em âmbito de pequenas ou miniagroindústrias, entende-se que essas mulheres devem passar a ser registradas como autônomas e não como pescadoras.

Neste ponto, cabe esclarecer que pescadores enquadram-se como “segurados especiais”, juntamente com aqueles que desempenham atividades rurais, haja vista sua profissão incorporar horários diferenciados, intempéries e desgaste físico precoce, e por isso mesmo acarreta que 
adquiram o direito à aposentaria em menor tempo do que o trabalhador urbano. Quando se trata das mulheres, porém, há a indicação, por parte dos técnicos, de que se enquadrem como autônomas, que por sua vez, por pressupor um trabalho urbano, demonstra sua inadequação, bem como reitera o processo de encobertamento da diversidade. Mais grave ainda quando essa adequação é proposta àquelas que trabalham como pescadoras embarcadas e por "direito" se equiparariam aos homens, como “seguradas especiais”. Nesse processo de enquadramento, as mulheres desaparecem como pescadoras e como "seguradas especiais", tornam-se invisíveis diante dos quadros formais e das estatísticas. Relegam seus direitos.

Como se não bastasse, tanto mulheres como homens da pesca estão sujeitos a um discurso, que a autora denomina de "sebraeniano", no qual há o estímulo para que se tornem empresários individuais. Esse estímulo, assim como a predisposição para o enquadramento como autônomos, incorpora um discurso que sugere a informalidade, e até mesmo a ilegalidade da atividade, como se o simples fato de "ser pescador" fosse uma categoria depreciativa em relação às demais.

Nos fios dessa rede tecida por Gerber, algumas temáticas são postas em relevo de forma secundária, mas que se revelam de grande importância para a construção da visibilização tanto da pesca artesanal quanto das mulheres.

Não obstante, vale evidenciar que embora haja um processo "natural” de mecanização dos modos de produção em geral, a fim de alcançar escala de produção, na pesca artesanal a máquina é recebida com desconfiança, sendo empregada apenas como um meio para suprir a falta de mão de obra nos processos de beneficiamento. Há, entre as pescadoras, $o$ consenso da inadequação das máquinas para que o trabalho seja realizado com a destreza e a qualidade necessárias, de acordo com os depoimentos: “A mulher, que tem mão, sente melhor”, “A máquina descasca sem sentir e 
então não faz um serviço perfeito como a mão da mulher”, "Deixa a casca junto, esmaga um pouco. Não é a mesma coisa” (Gerber, 2015, p. 158). Gerber ressalta, porém, ser este um processo inevitável, haja vista a mão de obra de mulheres nesse meio ter se tornado cada vez mais escassa.

Além disso, tornar-se um profissional da pesca é um processo informal, oral, afetivo e tradicional, o aprendizado ocorre diariamente pela prática e observação, pela troca de experiências e inovações com aqueles com os quais mantêm relações próximas, como consequência tecnologias e teorias científicas não são bem aceitas. "Ou seja, em seu cotidiano de testes, erros e acertos, arriscar alguma inovação advém do que se discute e se aprende com suas relações de confiança e proximidade, buscando uma aplicabilidade útil”. Destarte, não há regra no aprendizado, este é um processo circular que desdobra várias possibilidades (Gerber, 2015, p. 218).

É nesse sentido que se coloca em questão a legalização da violência contra as culturas tradicionais, que são coagidas a se adequarem aos padrões de industrialização, a fim de viabilizar uma cultura de mecanização, do branco, da limpeza, da melhor tecnologia e da melhor técnica, o que um dos pescadores definiu “como neurose do plástico" (Gerber, 2015, p. 151). Corrobora com esse cenário, a falta de incentivos fiscais e políticas públicas para a pesca artesanal em detrimento da pesca industrial.

Tais exemplos, trazidos por Gerber, são elucidativos para compreender como é restringido às mulheres pescadoras o direito de vivenciarem subjetivamente sua experiência na pesca como atividade profissional e social, aniquilando a diversidade nos modos singulares de ser e existir no mundo, a partir de um pressuposto burocrático de homogeneização. Do modo como a temática foi explorada pela autora, é evidente o retrocesso. A mulher da pesca, privada de reconhecimento, privada de sua singularidade, privada de possuir direitos, nos parece muito com a mulher descrita 
por Marshall (1967), que não poderia ser considerada como cidadã, no século 18, na Inglaterra, durante o processo de construção da cidadania. Uma violência velada, pretenciosa e escorregadia em pleno século 21.

Mais do que um livro indicado a antropólogos da pesca e feministas, como aludido por Sônia Weidner Maluf no prefácio do livro, também é uma obra que merece atenção de gestores públicos, técnicos, legisladores e juristas, na promoção e defesa dos direitos dessas mulheres na condição de pescadoras, bem como de outras culturas tradicionais. E finalmente, por servir de força motriz, para que seja evidenciado o processo pelo qual a igualdade vem pressupondo a aniquilação de diferenças, quando estas deveriam ser reconhecidas.

\section{REFERÊNCIAS}

GERBER, Rose Mary. Mulheres e o mar. pescadoras embarcadas, no litoral de Santa Catarina, sul do Brasil. Florianópolis: Editora UFSC, 2015.

MARSHALL, Thomas Humphrey. Cidadania, classe social e status. Rio de Janeiro: Zahar Editores, 1967.

Recebido em: 19/5/2016

Aceito em: 23/5/2016 